\title{
Orthostatic Decrease in Cardiac Chaos During the Head-up Tilt Test in Patients With Vasovagal Syncope
}

\author{
Masaru Suzuki, MD; Shingo Hori, MD; Yutaka Tomita, MD*; Naoki Aikawa, MD
}

\begin{abstract}
Background Autonomic dysfunction contributes to orthostatic intolerance in vasovagal syncope (VVS), but as it has not been identified by spectral analysis of heart rate variability (HRV) in previous studies, the present hypothesis was that nonlinear analysis of HRV would identify the orthostatic intolerance in VVS.

Methods and Results Twenty-six patients with VVS and 14 matched controls were subjected to 80-degree head-up tilt test (positive: 13 patients; negative: 13 patients and 14 controls). There were no differences in the orthostatic changes in the indices of spectral analyses of HRV among the 3 groups. The Lyapunov exponent (LE) was calculated from 200 consecutive RR-intervals to investigate chaotic behavior, and cardiac chaos was defined as the incidence of the presence of a positive finite LE. Orthostatic decreases in cardiac chaos were observed in the VVS patients (both the positive and negative groups), although there was no orthostatic decrease in the control group (ANOVA: $\mathrm{p}=0.008$ ). The receiver-operator characteristic curve indicated that cardiac chaos during the tilt identified VVS regardless of the results of the tilt ( $p<0.001$, sensitivity: $85.7 \%$, specificity: $96.2 \%$ ).

Conclusions The decrease in cardiac chaos during the tilt test was specific to patients with VVS, even if their response to the test was negative. (Circ J 2006; 70: 902-908)
\end{abstract}

Key Words: Autonomic nervous system; Heart rate variability; Syncope

$\mathbf{V}$ asovagal syncope (VVS) is a common manifestation of orthostatic intolerance in humans, ${ }^{1-7}$ and its diagnosis is made on the basis of the history, absence of any other proven etiology of the syncope, and a positive result for the head-up tilt test (HUT), ${ }^{1,4,5,8}$ Autonomic behavior during the HUT has been considered indispensable to understanding the elusive pathophysiology of VVS2,5,9 Previous studies have applied and assessed spectral analyses of heart rate variability (HRV) during the HUT in VVS patients ${ }^{10-15}$ and most have shown a correlation between the spectral analyses of HRV and the results of the HUT. However, the analyses failed to identify VVS patients when the results of the HUT were negative $!^{15}$

Traditional analyses of HRV have used noninvasive methods for assessing changes in autonomic activity, but they are incapable of analyzing the nonstationary fluctuations?,16 Techniques derived from nonlinear dynamics (eg, deterministic chaos) have complementary value in identifying patterns and mechanisms that cannot be detected by traditional statistic methods based on linear models! ${ }^{16-18}$ Because recent studies have indicated that some pathological conditions are accompanied by loss of chaos in the RR intervals (RRI) ${ }^{17-21}$ application of chaos theory to analysis of RRIs during the HUT may provide a new indicator of orthostatic intolerance. We hypothesized that the chaotic behavior of RRIs would identify the orthostatic intolerance in VVS.

(Received January 31, 2006; revised manuscript received March 27, 2006; accepted April 7, 2006)

Department of Emergency Medicine, School of Medicine, Keio University, Tokyo, *Department of Biosciences and Bioinformatics, Faculty of Science and Technology, Keio University, Yokohama, Japan

Mailing address: Masaru Suzuki, MD, Department of Emergency Medicine, Keio University, 35 Shinanomachi, Shinjuku-ku, Tokyo 160-8582, Japan.E-mail: suzuki@sc.itc.keio.ac.jp

\section{Methods}

Subjects

Twenty-six patients who presented to the emergency department with syncope and a history compatible with VVS participated in the present study. The diagnosis of VVS was confirmed by the history and/or tilt table testing according to the published guidelines on management of syncope. $\mathrm{Of}$ the 26 patients, 17 had a positive result for the HUT without any pharmacologic provocation, 4 had a positive result with pharmacologic provocation of isoproterenol infusion, and the remaining 5 each had a history compatible with VVS. None of the 26 patients had carotid sinus hypersensitivity or a history indicating situational syncope. They did not have hypertension, diabetes, or heart disease. The control group consisted of 14 healthy age- and gender-matched volunteers with no history of syncope (Table 1). All patients and volunteers gave their consent to participate before enrolment in the study. The study confirmed with the principles outlined in the World Medical Association's Declaration of Helsinki. The protocol and ethics were approved by the research committee of the Department of Emergency Medicine of Keio University Hospital.

\section{HUT}

The HUT was performed between $09.00-11.00 \mathrm{~h}$ in a quiet room at a controlled temperature $\left(23-25^{\circ} \mathrm{C}\right)$. Patients with VVS underwent the HUT 0-47 days (median: 3 days) after spontaneous syncopal episodes. The tilting table was manually driven and equipped with a footplate support. Following a control period of $20 \mathrm{~min}$ in the supine position, each subject was tilted to $80^{\circ}$ for a maximum of $30 \mathrm{~min}$ without the use of any provocative agents? If symptoms of impending syncope were elicited during the tilt, the patient was immediately returned to the supine position, and the test was stopped. A positive test was defined as the occur- 
Table 1 Characteristics of the Study Group

\begin{tabular}{|c|c|c|c|c|}
\hline & \multicolumn{2}{|c|}{ VVS patients } & \multirow[b]{2}{*}{$\begin{array}{c}\text { Controls } \\
(n=14)\end{array}$} & \multirow[b]{2}{*}{$p$ value } \\
\hline & $\begin{array}{c}\text { HUT positive group } \\
(n=13)\end{array}$ & $\begin{array}{c}\text { HUT negative group }{ }^{\dagger} \\
(n=13)\end{array}$ & & \\
\hline Males, number (\%) & $7(53.8)$ & $5(38.5)$ & $8(57.1)$ & 0.59 \\
\hline Age (years), mean $(S D)$ & $23.5(3.7)$ & $25.5(4.1)$ & $23.4(3.1)$ & 0.28 \\
\hline Syncopal episodes $*$, median (range) & $1(1-3)$ & $1(1-3)$ & None & - \\
\hline
\end{tabular}

VVS, vasovagal syncope; HUT, head-up tilt test.

$*$ Presyncopal episodes are not included; ${ }^{\dagger} 13$ patients had a negative result for HUT. In the HUT used to make a diagnosis of VVS, 4 patients had a positive result without provocation, 4 patients had a positive result using isoproterenol infusion; 5 patients had histories compatible with VVS.

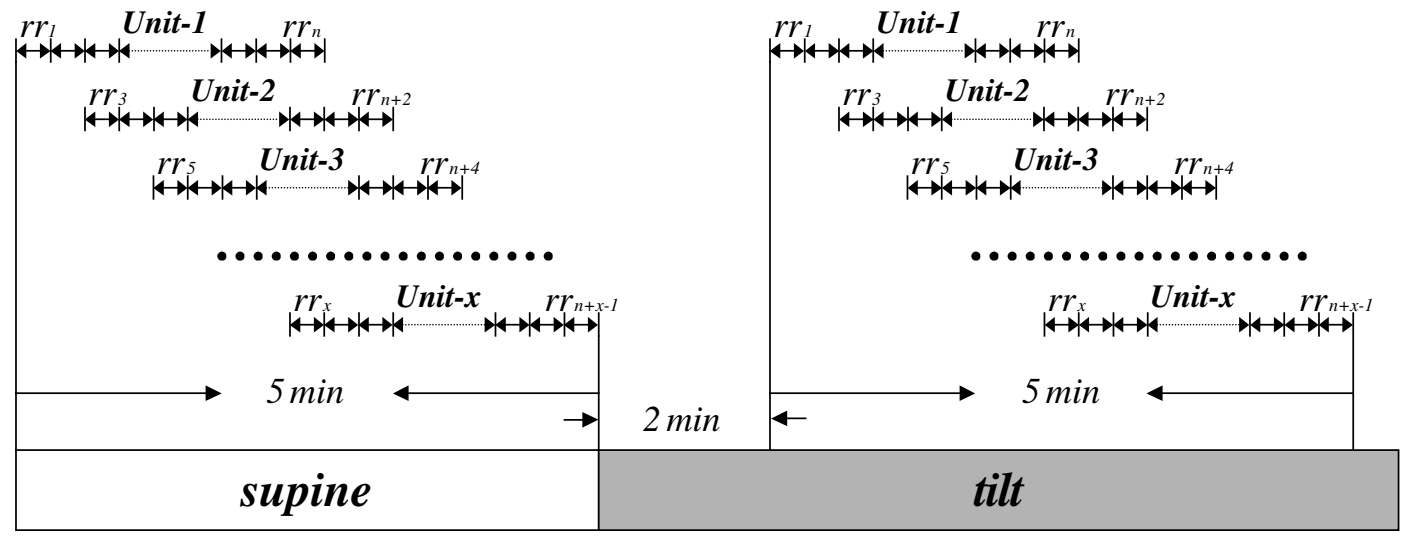

Fig 1. Extraction of the RR intervals (RRI) for calculating the Lyapunov exponent, which was calculated for units of consecutive RRI to investigate chaotic behavior. Consecutive units were extracted, shifting every 2 RRI, from 5-min RRI tracings recorded while supine and during tilting.

Table 2 AUC of the ROC for Diagnosing Vasovagal Syncope (Preliminary Study)

\begin{tabular}{cccc}
\hline \hline & Data points RR intervals & AUC $($ SE $)$ & $p$ value \\
\hline HUT & 25 & $0.50(0.10)$ & 1.00 \\
50 & $0.87(0.08)$ & $<0.001$ \\
100 & $0.93(0.05)$ & $<0.001$ \\
150 & $0.95(0.04)$ & $<0.001$ \\
200 & $0.97(0.02)$ & $<0.001$ \\
250 & $0.94(0.04)$ & $<0.001$ \\
300 & $0.94(0.03)$ & $<0.001$ \\
\hline
\end{tabular}

$A U C$, area under the curve; $R O C$, receiver-operating characteristic; SE, standard error; HUT, head-up tilt test.

rence of syncope or presyncope associated with an increase in the RRI of more than $3 \mathrm{~s}$ and/or a decrease in systolic arterial pressure of more than $30 \mathrm{mmHg}$ ?

\section{$H R V$}

During the HUT, the ECG was monitored with 2-lead chest electrodes (Lifescope $8^{\mathrm{TM}}$, Nihon Kohden, Tokyo, Japan), and finger arterial pressure was monitored with a plethysmographic device (Finapres ${ }^{\mathrm{TM}}$, Ohmeda, Englewood, CO, USA). Data were stored on a DAT tape (DAT recorder, RD-130TE ${ }^{\mathrm{TM}}$, TEAC, Tokyo, Japan), and the RRIs were obtained with Fluclet ${ }^{\mathrm{TM}}$ software (Dai-nippon Pharmaceutical, Osaka, Japan) running on a personal computer. This software computes the spectral analyses of HRV based on wavelet transform and provides a description of the spectral parameters every second. The highfrequency component (HF) of the RRIs, defined as 0.15$2.00 \mathrm{~Hz}\left(\mathrm{~ms}^{2} / \mathrm{Hz}\right)$, and the low-frequency component (LF),
Table 3 Orthostatic Changes in Arterial Pressure and RR Intervals

\begin{tabular}{lccc}
\hline \hline & $\begin{array}{c}\text { Supine } \\
\text { Mean } \pm S D\end{array}$ & $\begin{array}{c}\text { HUT } \\
\text { Mean } \pm S D\end{array}$ & $\begin{array}{c}\text { Repeated } \\
\text { ANOVA }\end{array}$ \\
\hline SAP (mmHg) & & & \\
VVS patients & & & \\
HUT positive group & $116 \pm 19$ & $107 \pm 34$ & $p=0.27$ \\
HUT negative group & $116 \pm 14$ & $117 \pm 13$ & \\
Normal control & $120 \pm 20$ & $120 \pm 14$ & \\
DAP (mmHg) & & & \\
VVS patients & $67 \pm 11$ & $71 \pm 11$ & \\
HUT positive group & $66 \pm 12$ & $73 \pm 13$ & $p=0.26$ \\
HUT negative group & $68 \pm 11$ & $73 \pm 10$ & \\
Normal control & & & \\
RRI (ms) & & & \\
VVS patients & $1,048 \pm 169$ & $807 \pm 104$ & \\
HUT positive group & & \\
HUT negative group & $928 \pm 111$ & $669 \pm 198$ & $p=0.39$ \\
Normal control & $1,000 \pm 162$ & $813 \pm 98$ & \\
\hline
\end{tabular}

$\overline{S A P, \text { systolic arterial pressure; DAP, diastolic arterial pressure; RRI, RR- }}$ interval. Other abbreviations see in Table 1.

defined as $0.04-0.15 \mathrm{~Hz}\left(\mathrm{~ms}^{2} / \mathrm{Hz}\right)$, were computed and measured? The standard deviation of RRIs (SDNN) was also calculated.

\section{Cardiac Chaos}

Whether the behavior of RRIs is chaotic can be determined by calculating the Lyapunov exponent (LE). The presence of a positive LE is strong evidence that the system is chaotic and not just quasi-periodic or periodic $22-24$ In the present study, LE was calculated thus: 

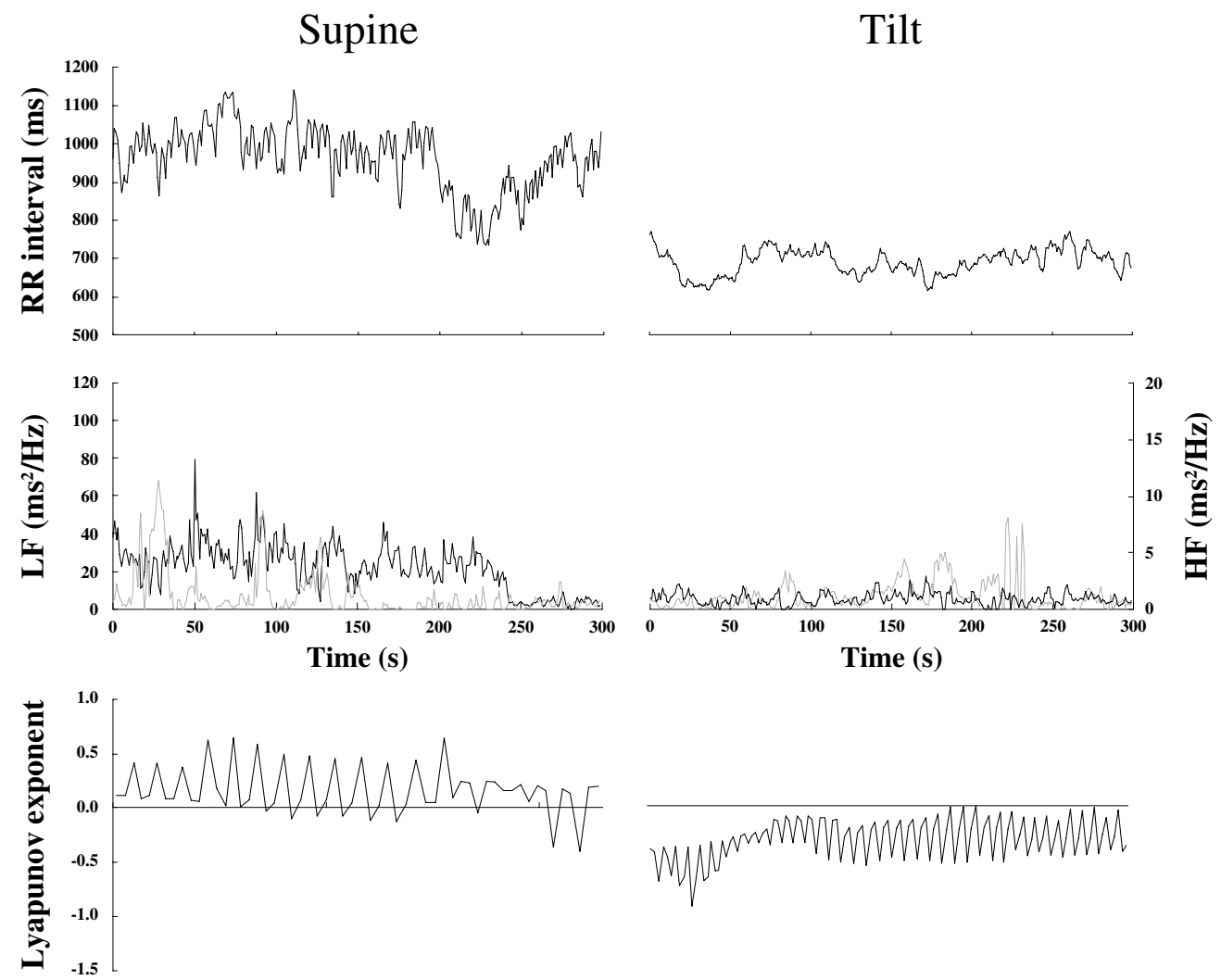

Fig 2. Time courses of the RR intervals (RRI) and heart rate variability (low-frequency component (LF), high-frequency component (HF), and Lyapunov exponent) in a vasovagal syncope patient with tilt-induced syncope. RRI, LF (gray lines), HF (black lines), and Lyapunov exponent are shown while supine (Left) and in the tilted position (Right). Positive Lyapunov exponents, which are strong evidence of chaos, were not observed in the tilted position.

$$
L E=\sum_{i=2}^{n-1} \log \frac{\left|r r_{i}-r r_{i+1}\right|}{\left|r r_{i-1}-r r_{i+1}\right|}
$$

The LE was calculated for units of consecutive RRIs (Fig 1). To quantify the chaotic behavior of the RRIs, the number of positive finite LEs during a 5-min tracing while supine and during the HUT was counted, and cardiac chaos was defined as the presence of a positive finite LE.

To choose the most suitable number of RRIs for identifying cardiac chaos, 25-300 RRIs were used to calculate LE in our preliminary study. Because the area under the receiver-operator characteristic (ROC) curve of cardiac chaos based on 200RRIs had the largest area (Table2), 200RRIs were used to calculate LE in this study.

\section{Data Analyses}

To study the orthostatic changes in hemodynamics and HRV parameters, including LF, HF, LF/HF, SDNN and cardiac chaos, 5-min RRI tracings while supine and during the HUT were recorded: (1) with the subject supine before the start of HUT, and (2) 2 min after the start of HUT. The duration of the RRI recording was set at $5 \mathrm{~min}$ in this study, because 5-min RRI recordings have been preferred in previous investigations of short-term HRV! 6

\section{Statistical Analysis}

The means of paired samples were analyzed by repeatedmeasures ANOVA, and the means of unpaired samples were analyzed by one-way ANOVA. The chi-square test was used for comparisons of categorical data. The assess- ment of the diagnostic accuracy of the HRV parameters and cardiac chaos was expressed by the ROC curve, being the area under the curve equal to the probability to discriminate from having or not having VVS. Thea level in the present study was 0.05 . All statistical analyses were performed using SPSSTM 12.0J software (SPSS Inc, Tokyo, Japan).

\section{Results}

\section{Results of the HUT}

The arterial pressure and RRI responses to the HUT are summarized in Table 3 . Of the 26 VVS patients, 13 experienced syncope and/or presyncope during the HUT (positive). There were no differences in the baseline characteristics of the patients with positive HUT results and those with negative results (Table 1). The positive responses were obtained $19.4 \pm 6.7 \mathrm{~min}$ (range: $8-29 \mathrm{~min}$ ) after the start of the HUT.

\section{Orthostatic Changes in HRV Parameters and LE}

Representative changes in the RRI, HF, LF, and LE are shown in Figs 2-4; the LE decreased during the HUT in the VVS patients, both those who had positive and negative HUT results (Figs 2,3), but did not decrease in the healthy volunteers (Fig 4).

There were no differences among the 3 groups in cardiac chaos while supine (Table 4). A significant orthostatic decrease in cardiac chaos was observed in the VVS patients $(p=0.008)$, but no orthostatic decrease was observed in the controls. There were no differences in the other parameters 

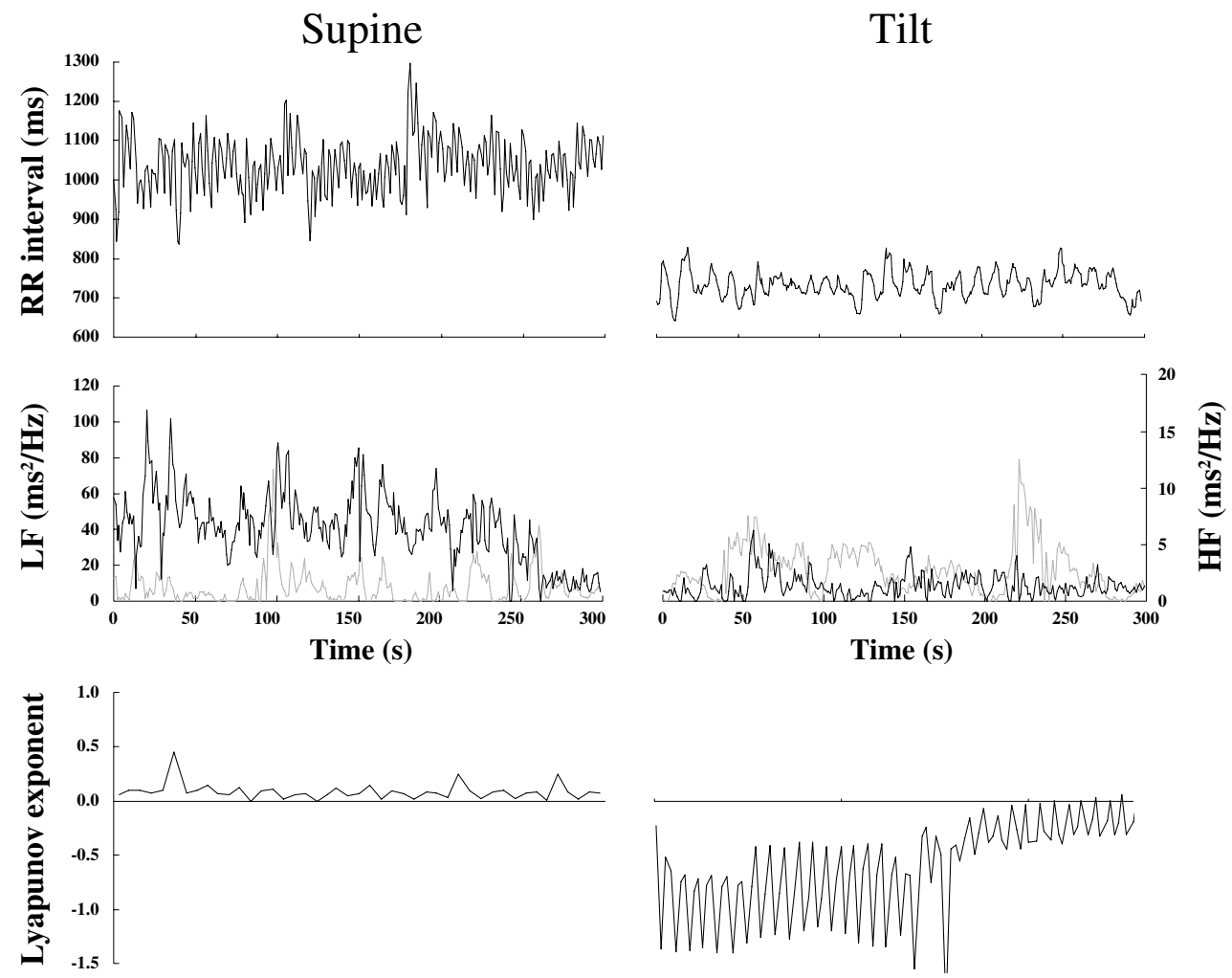

Fig 3. Time courses of the RR intervals (RRI) and heart rate variability (low-frequency component (LF), high-frequency component (HF), and Lyapunov exponent) in a vasovagal syncope patient without tilt-induced syncope. RRI, LF (gray lines), HF (black lines), and Lyapunov exponent are shown while supine (Left) and in the tilted position (Right). Positive Lyapunov exponents, which are strong evidence of chaos, were observed in the tilted position.
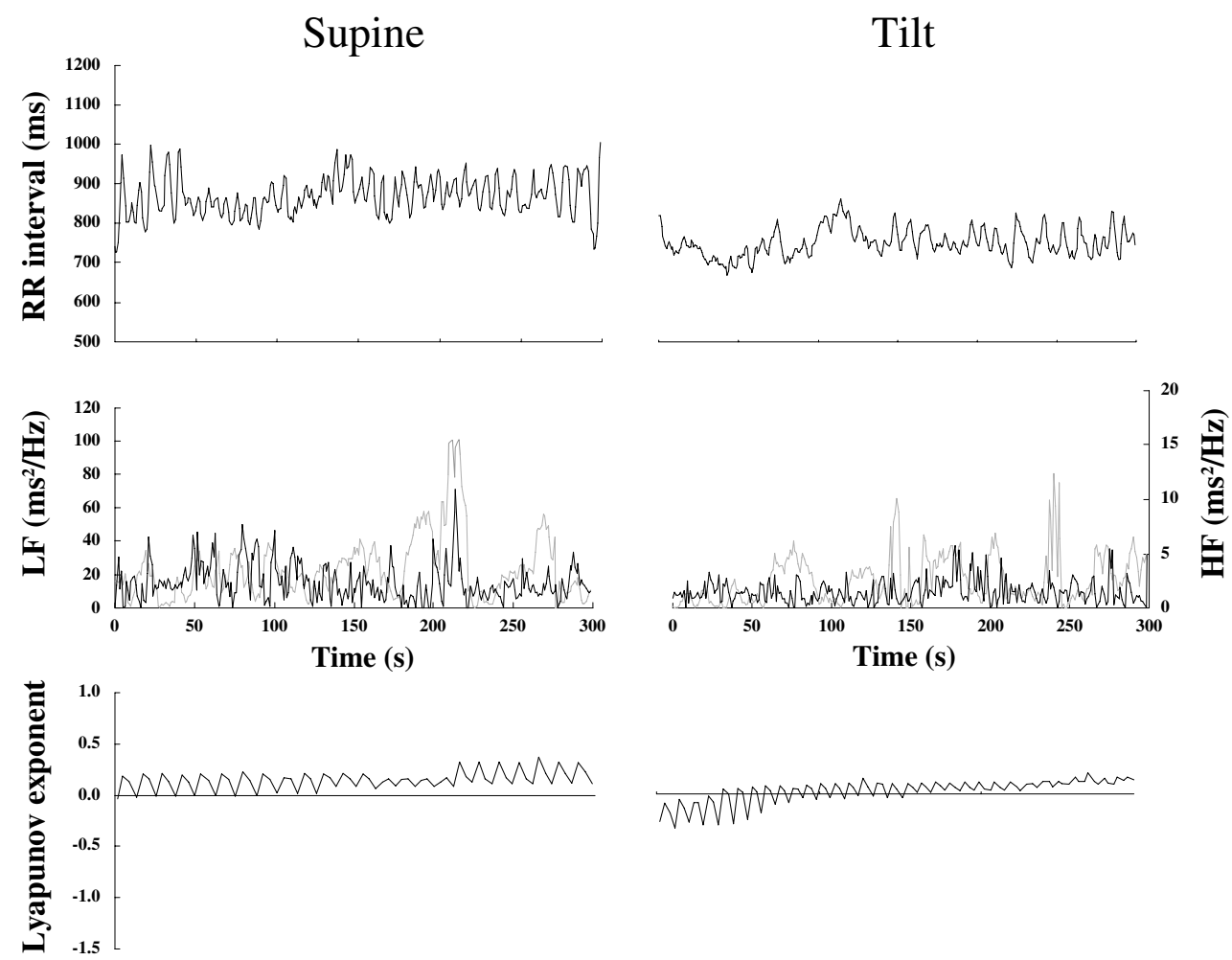

Fig 4. Time courses of RR intervals (RRI) and heart rate variability (low-frequency component (LF), high-frequency component (HF), and Lyapunov exponent) in a healthy control subject. RRI, LF (gray lines), HF (black lines), and Lyapunov exponent are shown while supine (Left) and in the tilted position (Right). Positive Lyapunov exponents, which are strong evidence of chaos, were observed in both positions. 
Table 4 Orthostatic Changes in Heart Rate Variability

\begin{tabular}{cccc}
\hline \hline & $\begin{array}{c}\text { Supine } \\
\text { Mean } \pm S D\end{array}$ & $\begin{array}{c}\text { HUT } \\
\text { Mean } \pm S D\end{array}$ & $\begin{array}{c}\text { Repeated } \\
\text { ANOVA }\end{array}$ \\
\hline Cardiac chaos (chaos/unit) & & & \\
VVS patients & & & \\
HUT positive group & $0.54 \pm 0.33$ & $0.15 * \pm 0.17$ & 0.008 \\
HUT negative group & $0.53 \pm 0.35$ & $0.13 \pm 0.10$ & \\
Normal control & $0.64 \pm 0.24$ & $0.57 \pm 0.25$ & \\
LF (ms s $^{\prime}$ Hz) & & & \\
VVS patients & & & \\
HUT positive group & $10.84 \pm 4.96$ & $7.52 \pm 3.03$ & 0.17 \\
HUT negative group & $9.31 \pm 3.95$ & $8.96 \pm 4.30$ & \\
Normal control & $11.95 \pm 7.12$ & $14.05 \pm 10.02$ & \\
HF (ms $/$ Hz) & & & \\
VVS patients & & & \\
HUT positive group & $7.06 \pm 5.18$ & $2.57 \pm 1.65$ & 0.42 \\
HUT negative group & $5.56 \pm 2.75$ & $2.31 \pm 1.72$ & \\
Normal control & $9.43 \pm 7.14$ & $4.12 \pm 2.72$ & \\
LF/HF & & & \\
VVS patients & & & \\
HUT positive group & $7.15 \pm 9.98$ & $19.67 \pm 20.67$ & 0.32 \\
HUT negative group & $4.62 \pm 4.39$ & $33.74 \pm 30.62$ & \\
Normal control & $9.24 \pm 22.40$ & $46.11 \pm 62.77$ & \\
SDNN & & & \\
VVS patients & & & \\
HUT positive group & $77.51 \pm 26.69$ & $63.92 \pm 22.61$ & 0.66 \\
HUT negative group & $55.13 \pm 12.11$ & $47.63 \pm 19.19$ & \\
*Normal control & $74.75 \pm 34.83$ & $57.58 \pm 17.54$ & \\
\hline
\end{tabular}

$L F$, low-frequency component; $H F$, high-frequency component; SDNN, standard deviation of RR-intervals. Other abbreviations see in Table 1.

${ }^{*} p=0.008$ vs normal control, ${ }^{\dagger} p=0.004$ vs normal control.

Table 5 AUC of the ROC for Diagnosing Vasovagal Syncope

\begin{tabular}{lcc}
\hline \hline Position and HRV & AUC $(S E)$ & $p$ value \\
\hline Supine & & \\
Cardiac chaos & $0.59(0.09)$ & 0.34 \\
LF & $0.56(0.11)$ & 0.57 \\
HF & $0.60(0.10)$ & 0.29 \\
LF/HF & $0.44(0.10)$ & 0.55 \\
SDNN & $0.55(0.10)$ & 0.61 \\
HUT & & \\
Cardiac chaos & $0.93(0.05)$ & $<0.001$ \\
LF & $0.72(0.09)$ & 0.02 \\
HF & $0.71(0.09)$ & 0.03 \\
LF/HF & $0.51(0.11)$ & 0.91 \\
SDNN & $0.55(0.09)$ & 0.64 \\
\hline
\end{tabular}

Abbreviations see in Tables 1,2,4.

\section{of HRV (Table 4).}

\section{Diagnosing VVS}

Area under the ROC curves were drawn to elucidate the diagnostic accuracy of the parameters, and they showed that cardiac chaos, LF, and HF during the HUT had significantly larger areas $(\mathrm{p}<0.001, \mathrm{p}=0.02, \mathrm{p}=0.03$, respectively). The parameters while supine were not predictive of VVS (Table 5).

Cardiac chaos during HUT had the largest area under the ROC curve (Fig 5). The optimal cutoff point for balancing sensitivity and specificity in cardiac chaos during the HUT was 0.36 (Fig 6), and at that cutoff value sensitivity was $92.3 \%$ and specificity was $96.3 \%$ (Table 6).

\section{Discussion}

In this study a decrease in cardiac chaos during the HUT

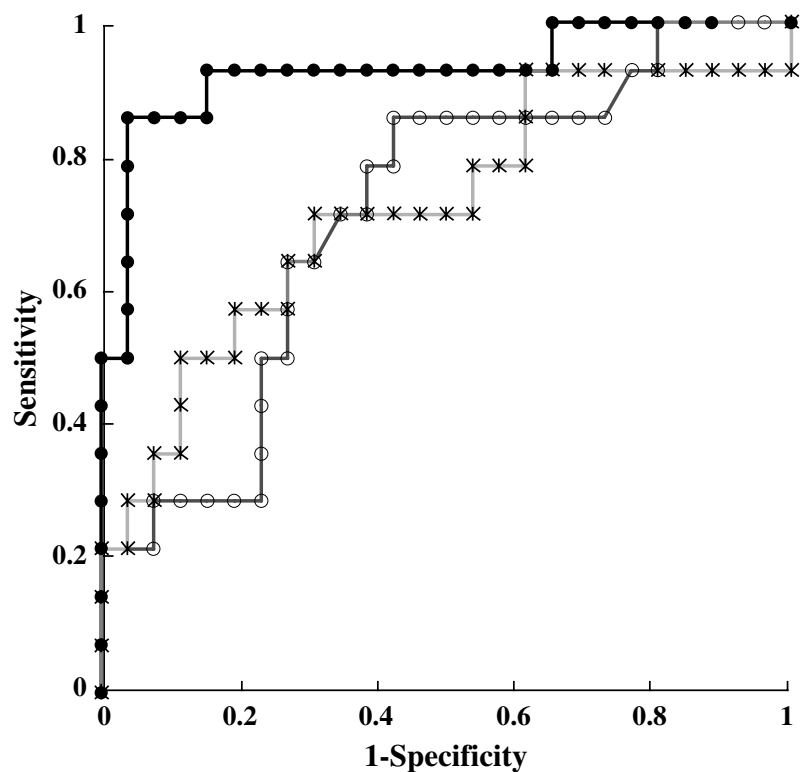

Fig 5. Receiver-operating characteristic curves for different strata of the indices of heart rate variability shown in Table4. (๑) Cardiac chaos, $(*)$ low-frequency component, $(\bigcirc)$ high-frequency component. The largest area under the curve is observed in cardiac chaos.

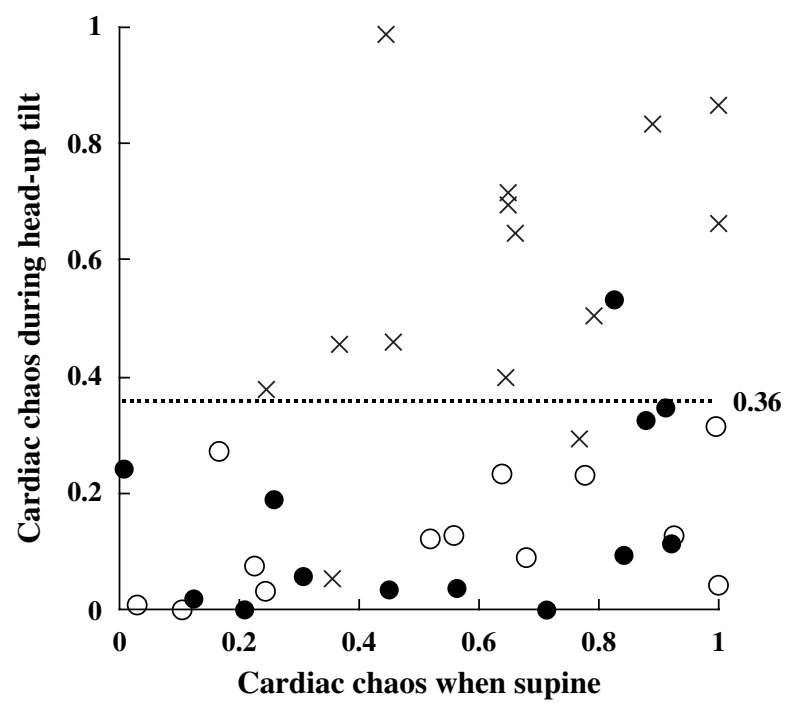

Fig 6. Relationship between cardiac chaos and the results of the head-up tilt test and position. Cardiac chaos in vasovagal syncope patients with $(\bigcirc)$ a negative head-up tilt test and $(\bullet)$ a positive head-up tilt test. $(\times)$ Cardiac chaos in healthy subjects. There were no differences among the 3 groups in cardiac chaos while supine, but cardiac chaos decreased in the patients when tilted regardless of the results of the head-up tilt test. A cutoff value of 0.36 is used in Fig 5 and Table 5 .

Table 6 Cutoff Values for the Diagnosis of VS

\begin{tabular}{lccc}
\hline \hline Heart rate variability & Cutoff value & Sensitivity & Specificity \\
\hline Cardiac chaos during HUT & 0.36 & $92.3 \%$ & $96.3 \%$ \\
LF during HUT $\left(\mathrm{ms}^{2} / \mathrm{Hz}\right)$ & 8.66 & $76.9 \%$ & $70.4 \%$ \\
HF during HUT $\left(\mathrm{ms}^{2} / \mathrm{Hz}\right)$ & 1.81 & $84.6 \%$ & $55.6 \%$ \\
\hline
\end{tabular}

Abbreviations see in Table 1,4. 
was observed in the VVS patients regardless of the outcome of the HUT, suggesting that the chaotic behavior of the RRIs in reaction to the gravitational load differs between healthy subjects and VVS patients.

Loss of heart rate complexity, as measured by the cardiac chaos, was a more sensitive indicator of orthostatic intolerance than conventional analysis measures, and this observation is consistent with the recent widely accepted hypothesis that chaotic behavior is characteristic of normal biological systems and that diminished complexity indicates pathology ${ }^{16,25-28}$ A positive effect of chaos in hemodynamic regulation may serve as a response to altered external influences. According to several studies, the transition from a physiological contribution of hemodynamic regulation to a pathological state is accompanied by a reduction in LE and loss of the degree of chaos, and this has been demonstrated in studies of multiple sclerosis ${ }^{24}$ and heart rate dynamics prior to sudden death? 20,21

Although the mechanism responsible for the cardiac chaos was not clarified in the present study, cardiovascular baroreceptor function may play a role. Intact cardiovascular regulation involves a long feedback loop ${ }^{29}$ and the major feedback loop is controlled by arterial and cardiopulmonary baroreceptors that regulate autonomic nervous tone ${ }^{21}$ This feedback has nonlinear response characteristics. After baroreceptor denervation, hemodynamic control is less complex and less sensitive on initial conditions ${ }^{30}$

Chaotic regulation may be advantageous in maintaining cardiovascular function in relation to gravitational load. Physiological systems normally operate to reduce variability and to maintain constancy of internal function, and the heart rate should return to its normal steady state after it has been altered. Chaotic systems operate under a wide range of conditions and are adaptable and flexible. This plasticity allows systems to cope with the exigencies of an unpredictable and changing environment 25,26

Previous studies have used different nonlinear measures during HUT19,31 One has reported that the LE values are not significantly different during tilt compared with supine posture in normal controls and patients with essential hypertension; 31 however, the subjects in that study were not syncopal patients. The other study indicated that there is a reduction of fractal dimension associated with presyncope during orthostatic stress using HUT and lower body negative pressure. 19 The reduction implies a loss of complexity in the underlying control of the heart rate response to orthostatic stress. These findings are compatible with the findings in the present study and represent the underlying complexity against which the cardiovascular system is able to recognize and respond to orthostatic stress.

A decrease in the chaotic behavior of the RRIs during HUT was observed in the VVS patients regardless of the outcome of the HUT, suggesting that the diagnostic yield of cardiac chaos is higher than that of the conventional HUT. The sensitivity and specificity of cardiac chaos for the diagnosis of VVS were greater than $85 \%$, whereas the sensitivity of the conventional HUT is approximately 40$60 \%$ !6,32,33 Recording the RRIs to analyze for cardiac chaos takes less than $10 \mathrm{~min}$, whereas the conventional HUT takes at least 30-60 min. 16,32 Thus, analysis of cardiac chaos is an easier and more accurate test than the conventional HUT for diagnosing VVS.

Analysis of linear statistics, such as time domain and frequency domain analyses, does not directly address the complexity of the RRIs, and thus may miss potentially helpful information. Because the underlying mechanisms involved in the control of the RRIs are mainly nonlinear, application of nonlinear techniques seems appropriate. The results of this study support the clinical utility of the analysis of chaos based on nonlinear dynamics.

\section{Study Limitations}

Some questions remain concerning the significance of the cardiac chaos in the present study.

First, the mechanism that generates cardiac chaos was not clarified in this study. Analysis of RRI dynamics by methods based on chaos theory and nonlinear system theory has recently attracted interest and is being steadily developed ${ }^{34}$ However, it is impossible to record all the variables that affect it, and the exact total number of degrees of freedom is unknown. These are fundamental problems in selecting a valid mathematical model for analysis of the RRIs, and thus their applicability to specific conditions should be tested for diagnostic and clinical purposes.

Second, a previous study reported that LE decreases with age 35 indicating that the RRIs become less chaotic as healthy subjects grow older. All of the subjects in the present study were young and healthy, and it is unknown whether our observations are valid for other age groups.

Third, the reproducibility and chronobiologic factors are crucial factors in determining the usefulness of this analysis as a diagnostic tool ${ }^{16,36}$ In fact, although the 8 of the 13 patients who were classified into the negative HUT group were diagnosed as VVS by positive HUT results with or without pharmacologic provocation (Table 1), orthostatic decreases of the cardiac chaos were observed during negative HUT response. This suggests that the analysis is reproducible; however, the reproducibility and chronobiology were not thoroughly evaluated in the present study. Further study is needed to elucidate the issue regarding reproducibility and chronobiology.

Fourth, 15 of the 26 VVS patients underwent the HUT within 5 days of spontaneous syncopal episodes. Their autonomic function may have been disturbed by the spontaneous syncopal attack. Our limited preliminary data suggested that a short period between spontaneous syncope and the HUT did not affect on the cardiac chaos, but this study was not designed to elucidate the impact of a spontaneous syncopal attack on cardiac chaos.

Finally, because there were no data for chaotic analysis of the RRIs in other types of orthostatic intolerance, including orthostatic hypotension, it is unknown whether our observations are applicable to the pathophysiology of other diseases.

\section{Conclusions}

A decrease in cardiac chaos during the HUT was specific to VVS patients, even when their response to the HUT was negative. Cardiac chaos may indicate adaptation to orthostatic stress, and the orthostatic decrease may play a role in the pathophysiology of VVS.

\section{References}

1. Kapoor WN. Syncope. N Engl J Med 2000; 343: 1856-1862.

2. Suzuki M, Hori S, Nakamura I, Nagata S, Tomita Y, Aikawa N. Role of vagal control in vasovagal syncope. Pacing Clin Electrophysiol 2003; 26: $571-578$.

3. Suzuki M, Hori S, Nakamura I, Soejima K, Aikawa N. Long-term survival of Japanese patients transported to an emergency depart- 
ment because of syncope. Ann Emerg Med 2004; 44: 215-221.

4. Brignole M, Alboni P, Benditt D, Bergfeldt L, Blanc JJ, Bloch Thomsen PE, et al. Guidelines on management (diagnosis and treatment) of syncope. Eur Heart J 2001; 22: 1256-1306.

5. Fenton AM, Hammill SC, Rea RF, Low PA, Shen WK. Vasovagal syncope. Ann Intern Med 2000; 133: 714-725.

6. Kim KH, Cho JG, Lee KO, Seo TJ, Shon CY, Lim SY, et al. Usefulness of physical maneuvers for prevention of vasovagal syncope. Circ J 2005; 69: 1084-1088.

7. Suwa S, Sumiyoshi M, Mineda Y, Ohta H, Kojima S, Nakata Y. Vasovagal response induced by a low dose of isoproterenol infusion before tilting-up. Circ J 2004; 68: 876-877.

8. Benditt DG, Ferguson DW, Grubb BP, Kapoor WN, Kugler J, Lerman BB, et al. Tilt table testing for assessing syncope. J Am Coll Cardiol 1996; 28: 263-275.

9. Mosqueda-Garcia R, Furlan R, Tank J, Fernandez-Violante R. The elusive pathophysiology of neurally mediated syncope. Circulation 2000; 102: 2898-2906.

10. Kouakam C, Lacroix D, Zghal N, Logier R, Klug D, Le Franc P, et al. Inadequate sympathovagal balance in response to orthostatism in patients with unexplained syncope and a positive head up tilt test. Heart 1999; 82: 312-318.

11. Stewart JM, Erb M, Sorbera C. Heart rate variability and the outcome of head-up tilt in syncopal children. Pediatr Res 1996; 40: 702-709.

12. Piccirillo G, Naso C, Moise A, Lionetti M, Nocco M, Di Carlo S, et al. Heart rate and blood pressure variability in subjects with vasovagal syncope. Clin Sci (Lond) 2004; 107: 55-61.

13. Morillo CA, Klein GJ, Jones DL, Yee R. Time and frequency domain analyses of heart rate variability during orthostatic stress in patients with neurally mediated syncope. Am J Cardiol 1994; 74: 1258-1262.

14. Boulos M, Barron S, Nicolski E, Markiewicz W. Power spectral analysis of heart rate variability during upright tilt test: A comparison of patients with syncope and normal subjects. Cardiology 1996; 87: $28-32$.

15. Kochiadakis GE, Kanoupakis EM, Igoumenidis NE, Marketou ME, Solomou MC, Vardas PE. Spectral analysis of heart rate variability during tilt-table testing in patients with vasovagal syncope. Int $J$ Cardiol 1998; 64: 185-194.

16. Task Force of the European Society of Cardiology and the North American Society of Pacing and Electrophysiology. Heart rate variability: Standards of measurement, physiological interpretation and clinical use. Circulation 1996; 93: 1043-1065.

17. Huikuri HV, Makikallio TH, Peng CK, Goldberger AL, Hintze U, Moller M. Fractal correlation properties of R-R interval dynamics and mortality in patients with depressed left ventricular function after an acute myocardial infarction. Circulation 2000; 101: 47-53.

18. Mahon NG, Hedman AE, Padula M, Gang Y, Savelieva I, Waktare $\mathrm{JE}$, et al. Fractal correlation properties of R-R interval dynamics in asymptomatic relatives of patients with dilated cardiomyopathy. Eur J Heart Fail 2002; 4: 151-158.
19. Butler GC, Yamamoto Y, Xing HC, Northey DR, Hughson RL. Heart rate variability and fractal dimension during orthostatic challenges. J Appl Physiol 1993; 75: 2602-2612.

20. Skinner JE, Pratt CM, Vybiral T. A reduction in the correlation dimension of heartbeat intervals precedes imminent ventricular fibrillation in human subjects. Am Heart J 1993; 125: 731 - 743 .

21. Goldberger AL. Fractal electrodynamics of the heartbeat. Ann NY Acad Sci 1990; 591: 402-409.

22. Persson PB, Wagner CD. General principles of chaotic dynamics. Cardiovasc Res 1996; 31: 332-341.

23. Goldberger AL. Non-linear dynamics for clinicians: Chaos theory, fractals, and complexity at the bedside. Lancet 1996; 347: 13121314.

24. Ganz RE, Weibels G, Stacker KH, Faustmann PM, Zimmermann $\mathrm{CW}$. The Lyapunov exponent of heart rate dynamics as a sensitive marker of central autonomic organization: An exemplary study of early multiple sclerosis. Int J Neurosci 1993; 71: 29-36.

25. Lombardi F. Chaos theory, heart rate variability, and arrhythmic mortality. Circulation 2000; 101: 8-10.

26. Otero-Siliceo E, Arriada-Mendicoa N. Is it healthy to be chaotic? Med Hypotheses 2003; 60: 233-236.

27. Griffith TM. Temporal chaos in the microcirculation. Cardiovasc Res 1996; 31: $342-358$.

28. Skinner JE, Carpeggiani C, Landisman CE, Fulton KW. Correlation dimension of heartbeat intervals is reduced in conscious pigs by myocardial ischemia. Circ Res 1991; 68: 966-976.

29. Denton TA, Diamond GA, Helfant RH, Khan S, Karagueuzian H. Fascinating rhythm: A primer on chaos theory and its application to cardiology. Am Heart J 1990; 120: 1419-1440.

30. Wagner CD, Nafz B, Persson PB. Chaos in blood pressure control. Cardiovasc Res 1996; 31: 380-387.

31. Kagiyama S, Tsukashima A, Abe I, Fujishima S, Ohmori S, Onaka $\mathrm{U}$, et al. Chaos and spectral analyses of heart rate variability during head-up tilting in essential hypertension. J Auton Nerv Syst 1999; 76: $153-158$.

32. Stein KM, Slotwiner DJ, Mittal S, Scheiner M, Markowitz SM, Lerman BB. Formal analysis of the optimal duration of tilt testing for the diagnosis of neurally mediated syncope. Am Heart J 2001; 141: $282-288$.

33. Kapoor WN. Using a tilt table to evaluate syncope. Am J Med Sci 1999; 317: $110-116$

34. Huikuri HV, Makikallio TH, Perkiomaki J. Measurement of heart rate variability by methods based on nonlinear dynamics. $J$ Electrocardiol 2003; 36(Suppl): 95-99.

35. Acharya UR, Kannathal N, Sing OW, Ping LY, Chua T. Heart rate analysis in normal subjects of various age groups. Biomed Eng Online 2004; 3: 24.

36. Hosaka H, Takase B, Katsushika S, Ohsuzu F, Kurita A. Altered fractal behavior and heart rate variability in daily life in neurally mediated syncope. Biomed Pharmacother 2003; 57(Suppl 1): 77s-82s. 